\title{
Hétérogénéité antivirale constitutive au sein de l'hôte, une écologie propice à la réparation tissulaire post-infectieuse ?
}

\author{
Denis Gerlier \\ CIRI, International Center for \\ Infectiology Research, Inserm U1111, \\ Université Claude Bernard Lyon 1, \\ CNRS, UMR5308, École normale \\ supérieure de Lyon, Univ Lyon, \\ Lyon, France
}

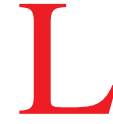
es étapes initiales de l'infection virale sont cruciales pour son devenir. En dehors de l'expression ou non d'un récepteur cellulaire capable d'assurer la fixation du virus et sa pénétration, la permissivité d'une cellule hôte est aussi étroitement contrôlée par l'expression endogène constitutive de protéines antivirales plus connues sous le vocable « facteurs de restriction intrinsèque ». Ces facteurs de restrictions ont d'abord été mis en évidence en particulier chez les rétrovirus pour définir une résistance génétique à une infection soit au sein d'une même espèce, soit entre espèces phylogénétiquement proches comme cela est bien documenté pour les lentivirus infectant les primates [1]. Ainsi, une sous-population cellulaire - monocytes et macrophages du sang circulant peut exprimer sélectivement le facteur de restriction SAMHD1. Cela la rend non permissive au virus de l'immunodéficience humaine (VIH1) [2]. Au contraire, l'expression constitutive de l'ubiquitin specific peptidase 18 (USP18) une deubiquitinase responsable du rétrocontrôle négatif de la réponse interféron de type I rend les macrophages sous-capsulaires des ganglions lymphatiques très permissifs au virus de la stomatite vésiculaire (VSV) [3].

L'autre famille d'effecteurs antiviraux est constituée par une large palette de gènes inductibles essentiellement sous le contrôle de l'axe interféron de type I ou III (IFN) et de leur récepteur, appelés « interferon signaling gene » (ISG). Les ISGs sont activés par l'IFN produit par une cellule en réplique à un stimulus viral via l'activation de son immunité innée intrinsèque. En réalité, la dichotomie entre facteurs intrinsèques et facteurs induits, reflétant également une divergence fonctionnelle séparant historiquement les points de vue du virologiste et de l'immunologiste, ne représente pour l'essentiel que deux facettes d'un même arsenal antiviral cellulaire. En effet, les facteurs de restriction sont aussi des ISGs et nombre d'ISGs sont exprimés à l'état basal [4]. Ils peuvent même devenir constitutifs au cours de la différenciation cellulaire. Par exemple, IFMT3 est exprimé dans les lymphocytes CD8(+) mémoires résidents du parenchyme pulmonaire, ce qui assure leur invulnérabilité contre le virus influenza [5]. L'expression constitutive de SAMHD1, facteur de restriction des rétrovirus, par le macrophage d'origine myéloïde, en est une autre illustration [6].

Une telle variation de permissivité selon le type cellulaire s'est encore accrue avec l'observation de Swartzendruber et Lehman : les cellules pluripotentes d'un tératocarcinome indifférencié murin sont non-permissives à l'infection par un virus polyome (SV40, PyV), et cette résistance est perdue après leur différenciation spontanée in vitro [7], observation confirmée depuis. Cette résistance n'est cependant pas absolue car les cellules indifférenciées sont permissives à un Alphavirus, le Semliki forest virus (SFV). Étrangement, les cellules indifférenciées embryonnaires ni ne produisent d'IFN après infection virale ou activation par du Poly(I:C), ni ne répondent à l'IFN de manière à bloquer l'infection par le SFV bien qu'il soit réputé particulièrement sensible à l'IFN [8].

Depuis la fin $\mathrm{du} \mathrm{xx}^{\mathrm{e}}$ siècle est intervenu un extraordinaire développement couplé d'analyses moléculaires à l'échelle de la cellule unique et de cultures contrôlées de cellules souches totipotentes embryonnaires ou de cellules souches de l'adulte et de leurs progénitures dans un état de différenciation plus 
ou moins avancé, de multi- à pauci-potentes allant jusqu'à la différenciation terminale constitutive de chacun des tissus de l'organisme. Ces avancées technologiques ont permis une analyse extensive de cellules souches plus ou moins différenciées. Cela permit de confirmer l'absence de permissivité des cellules souches vis-à-vis d'une panoplie de virus, et l'acquisition progressive d'une permissivité lors des différentes étapes de la différenciation [9]. Le mécanisme sous-jacent est en partie décrypté avec la corrélation fonctionnelle entre la non-permissivité et l'expression constitutive d'un sous-groupe d'ISG. Les ISGs connus pour réguler négativement le cycle cellulaire ou pour induire l'apoptose en sont logiquement exclus. Cette dynamique de résistance/permissivité étant conservée chez les espèces de mammifères explorées, son importance dans l'écologie des infections virales au cours du développement et chez l'adulte pour permettre la réparation tissulaire post-infectieuse et préserver l'auto-régénération tissulaire apparaît alors primordiale. Dans ce contexte, quel est le mécanisme sous-jacent au pouvoir tératogène du virus de la rubéole ? L'embryon infecté est en effet caractérisé par une diminution du nombre de cellules [10]. Compte-tenu de la grande hétérogénéité du patron d'expression constitutive des ISGs selon l'état de différenciation de chaque cellule de l'embryon et son origine tissulaire, l'appauvrissement cellulaire induit par ce virus est-il consécutif à une ablation sélective de certaines cellules souches, au blocage de leur différenciation ou à une destruction sélective de certaines cellules différenciées?
Liens d'intérêts: L'auteur déclare n'avoir aucun lien d'intérêt en rapport avec cet article.

\section{Références}

1. D'Arc M, Ayouba A, Esteban A, et al. Origin of the HIV-1 group $\mathrm{O}$ epidemic in western lowland gorillas. Proc Natl Acad Sci US A $2015 ; 112$ : E1343-52.

2. Laguette N, Benkirane M. How SAMHD1 changes our view of viral restriction. Trends Immunol $2012 ; 33: 26-33$.

3. Honke N, Shaabani N, Cadeddu G, et al. Enforced viral replication activates adaptive immunity and is essential for the control of a cytopathic virus. Nat Immunol $2011 ; 13: 51-7$

4. Schneider WM, Chevillotte MD, Rice CM. Interferon-stimulated genes: a complex web of host defenses. Апnи Rev Immunol 2014; 32 : 513-45.

5. Wakim LM, Gupta N, Mintern JD, Villadangos JA. Enhanced survival of lung tissue-resident memory $\mathrm{CD} 8(+) \mathrm{T}$ cells during infection with influenza virus due to selective expression of IFITM3. Nat Immunol $2013 ; 14: 238-45$.

6. Laguette N, Sobhian B, Casartelli N, et al. SAMHD1 is the dendriticand myeloid-cell-specific HIV-1 restriction factor counteracted by Vpx. Nature $2011 ; 474: 654-7$.

7. Swartzendrube DE, Lehman JM. Neoplastic differentiation: interaction of simian virus 40 and polyoma virus with murine teratocarcinoma cells in vitro. J Cell Physiol $1975 ; 85: 179-87$.

8. Burke DC, Graham CF, Lehman JM. Appearance of interferon inducibility and sensitivity during differentiation of murine teratocarcinoma cells in vitro. Cell $1978 ; 13: 243-8$.

9. Wu X, Dao Thi VL, Huang Y, et al. Intrinsic Immunity Shapes Viral Resistance of Stem Cells. Cell 2018; 172: 423-38.

10. Naeye RL, Blanc W. Pathogenesis of congenital rubella. JAMA $1965 ; 194: 1277-83$. 


\section{éditorial}

Coordinateurs
Pr Serge Paul Eholié
CHU de Treichville, Abidjan,
Côte d'voire
-Pr Pierre-Marie Girard
Hôpital Saint-Antoine, Paris,
France

\section{No More Plaque Assays!}

\section{A whole new way to monitor viral cytopathic effects (CPE) with $x C E L L$ igence ${ }^{\circledR}$ RTCA}

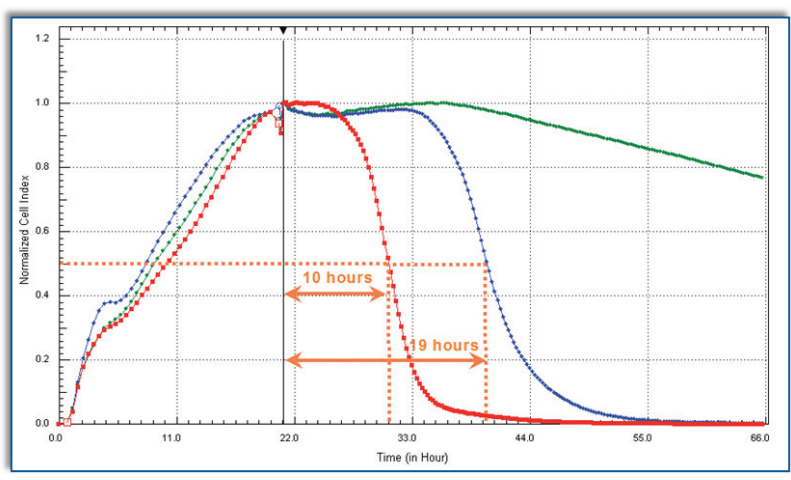

Real-time monitoring of VSV-induced CPE. Normalized cell index (CI) is plotted as a function of time post infection of Vero cells inoculated with different PFU of VSV (blue: 80,000 PFU; red: 800,000 PFU) and uninfected cells (green). Time of addition of virus is indicated by the black vertical line. The time point when $\mathrm{Cl}$ value had decreased to $50 \%$ of the maximum $(\mathrm{Cl} 50)$ value is indicated by the dotted orange lines.

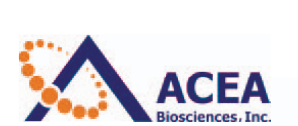

Jérome Darakdjian

ACEA Biosciences, Inc.

Mobile: +33(0)6 35275241

Email: jdarakdjian@aceabio.com
- Label Free: No markers or dyes required.

- Fast: Read an entire 96-well plate in just 10 to 15 , seconds. No scheduling conflicts with other plates and assays.

- Real Time Kinetic Readouts: You define the time points in seconds, minutes, hours, or days.

- Easy Work Flow: Simply plate and go.

- Safety: Mitigates the risk of exposure

- Accurate, Precise, and Highly Reproducible.

- The Intuitive xCELLigence ${ }^{\circledR}$ Software does the rest.
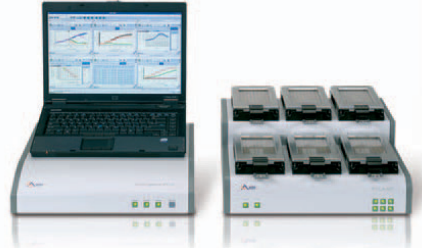

The Cell Analysis Company 